\title{
Association Mapping of Quantitative Resistance to Phaeosphaeria nodorum in Spring Wheat Landraces from the USDA National Small Grains Collection
}

\author{
Tika B. Adhikari, Eric W. Jackson, Suraj Gurung, Jana M. Hansen, and J. Michael Bonman
}

First, third, and fourth authors: Department of Plant Pathology, North Dakota State University, Department 7660, P.O. Box 6050, Fargo, ND 58108; second and fifth authors: United States Department of Agriculture-Agricultural Research Service, Small Grains and Potato Germplasm Research Unit, Aberdeen, ID 83210.

Current address of the third author: Department of Plant Pathology, University of California, Davis, c/o U.S. Agricultural Research Station, 1636 E. Alisal Street, Salinas, CA 93905.

Accepted for publication 10 June 2011.

\begin{abstract}
Adhikari, T. B., Jackson, E. W., Gurung, S., Hansen, J. M., and Bonman, J. M. 2011. Association mapping of quantitative resistance to Phaeosphaeria nodorum in spring wheat landraces from the USDA National Small Grains Collection. Phytopathology 101:1301-1310.

Stagonospora nodorum blotch (SNB), caused by Phaeosphaeria nodorum, is a destructive disease of wheat (Triticum aestivum) found throughout the United States. Host resistance is the only economically feasible option for managing the disease; however, few SNB-resistant wheat cultivars are known to exist. In this study, we report findings from an association mapping (AM) of resistance to P. nodorum in 567 spring wheat landraces of diverse geographic origin. The accessions were

evaluated for seedling resistance to $P$. nodorum in a greenhouse. Phenotypic data and 625 polymorphic diversity array technology (DArT) markers have been used for linkage disequilibrium (LD) and association analyses. The results showed that seven DArT markers on five chromosomes $(2 \mathrm{D}, 3 \mathrm{~B}, 5 \mathrm{~B}, 6 \mathrm{~A}$, and $7 \mathrm{~A})$ were significantly associated with resistance to $P$. nodorum. Genetic regions on $2 \mathrm{D}, 3 \mathrm{~B}$, and $5 \mathrm{~B}$ correspond to previously mapped quantitative trait loci (QTL) conferring resistance to $P$. nodorum whereas the remaining QTL appeared to be novel. These results demonstrate that the use of AM is an effective method for identifying new genomic regions associated with resistance to $P$. nodorum in spring wheat landraces. Additionally, the novel resistance found in this study could be useful in wheat breeding aimed at controlling SNB.
\end{abstract}

Stagonospora nodorum blotch (SNB), caused by Phaeosphaeria nodorum (E. Müll.) Hedjar. (anamorph: Stagonospora nodorum (Berk.) E. Castell. \& Germano, syn. Septoria nodorum), is an important disease of wheat (Triticum aestivum L.) worldwide $(16,17)$. SNB infects both leaves and glumes and subsequently causes grain quality and yield losses $(21,32,54)$. At least five hostselective toxins (HSTs) have been identified in the P. nodorumwheat pathosystem $(22,23,34,35)$, and each of these HSTs interacts with a corresponding host sensitivity gene in an inverse genefor-gene manner $(1,22)$.

Traditionally, biparental populations derived from crosses between SNB-resistant and SNB-susceptible wheat cultivars have been used to identify quantitative trait loci (QTL) for seedling resistance to $P$. nodorum using either single or mixtures of isolates $(1,13,27,34)$. However, QTL for flag leaf resistance $(3,22,47)$ and for glume resistance $(3,46,47,52)$ were identified on different wheat chromosomes when mapping populations were tested in field environments. For example, two major QTL, QSng.sfr-3BS and $Q s n b . f c u-1 A$, conferring resistance to Stagonospora nodorum glume blotch, and Stagonospora nodorum leaf blotch, respectively, have been identified in a population derived from a cross between two Swiss wheat cultivars ('Arina' and 'Forno') $(1,51)$. Similarly, other QTL have been identified based on interactions between wheat genes conferring sensitivity or susceptibility to

Corresponding author: T. B. Adhikari; E-mail address: tika.adhikari@ndsu.edu or tadhikari31@yahoo.com

* The $\boldsymbol{e}$-Xtra logo stands for "electronic extra" and indicates that the online version contains two supplementary tables.

doi:10.1094/PHYTO-03-11-0076

(c) 2011 The American Phytopathological Society
HSTs produced by $P$. nodorum (22). It also appeared that genes controlling resistance to seedling, flag leaf, and glume resistance are independent. Although biparental linkage analysis has been successful in identifying candidate QTL, some major disadvantages exist with this approach. Developing biparental mapping populations requires considerable time, and discovery of novel resistances is limited by whatever resistance genes are present in the two parents.

Association mapping (AM) is a good alternative to biparental mapping because it uses linkage disequilibrium (LD) between alleles within diverse populations to identify marker-trait associations alleviating the time and cost of developing populations. Additionally, AM takes into account greater allelic diversity at a given locus when using genetic markers capable of characterizing the variability. Because AM utilizes LD, accounting for the structure of a population is highly important to reduce chimeric associations $(39,49)$. Recently, new computational software and improved statistical methods have been developed and have advanced our understanding of the accurate assessment of markertrait associations in complex pedigree populations (29,51). These statistical tools include mixed linear models (MLMs) $(56,59)$, Bayesian clustering (43) or principal component analysis (PCA) (42), and Q+K mixed models (56).

Association analysis has been successfully applied to identify marker-trait associations in different crops $(6,33,40,45,55)$. Additionally, association analysis uses preexisting germplasm such as landraces, modern cultivars, and advanced breeding lines to detect potential associations between molecular markers and traits of interest (59). In wheat, an AM approach has been used to map agronomic and quality traits such as kernel size and milling quality (10), grain yield (12), high-molecular-weight glutenin (44), 
resistance to foliar diseases $(12,28)$, and Fusarium head blight (FHB) resistance (40).

The main objectives of this study were to evaluate a subset of 567 geographically diverse spring wheat landraces from the National Small Grains Collection (NSGC), United States Department of Agriculture-Agricultural Research Service (USDA-ARS) for quantitative resistance to $P$. nodorum and characterize the genetic of resistance to $P$. nodorum using diversity array technology (DArT) markers and AM. The results showed significant associations between DArT markers and SNB phenotypes on various wheat chromosomes, some of which are novel based on comparison. This work should lead to novel resistance QTL ready for introgression via marker-assisted selection (MAS). However, it is necessary to verify the identified candidate genetic regions prior to using them in MAS.

\section{MATERIALS AND METHODS}

Wheat accessions. In total, 567 spring habit wheat accessions from the NSGC used in a previous association analysis for races 1 and 5 of Pyrenophora tritici-repentis (28) were analyzed in this study. All of the accessions were classified as landraces and 533 were part of the wheat core subset, which was chosen to represent accessions of diverse geographic origin.

Inoculum preparation and inoculation. Isolate $\mathrm{Sn} 2000$ of $P$. nodorum, collected from a wheat field in North Dakota, was used in this study. Inoculum was prepared as described previously (37), with some modifications. Briefly, three to four mycelium plugs stored in the freezer were placed in the center of each petri dish containing V8-potato dextrose agar (V8-PDA) $(150 \mathrm{ml}$ of V8 juice, $10 \mathrm{~g}$ of dextrose, $10 \mathrm{~g}$ of agar, $3 \mathrm{~g}$ of calcium carbonate, and $850 \mathrm{ml}$ of water). The plates were incubated at $21^{\circ} \mathrm{C}$ in darkness for 5 days and then subjected to continuous light for 6 days to enhance sporulation. Mature fungal cultures were flooded with $20 \mathrm{ml}$ of sterile distilled water and scraped with a sterile glass slide to loosen and release oozing pycnospores. The resulting suspension was filtered through four layers of cheesecloth and the spore concentration was adjusted to $1 \times 10^{6} / \mathrm{ml}$ using a hemacytometer. Before inoculation, a drop of Tween 20 (polyoxyethylene-20-sorbitan monolaurate) was added in $100 \mathrm{ml}$ of inoculum suspension to reduce surface tension and facilitate uniform spore deposition onto leaves after inoculation.

Phenotyping. Nine seeds of an accession were planted in groups of three in individual plastic conetainers $(3.8 \mathrm{~cm}$ in diameter and $20 \mathrm{~cm}$ long) containing sunshine mix number 1 (Fision Horticulture, Vancouver, BC, Canada) and $2.5 \mathrm{~g}$ of a slow-release commercial fertilizer (Multicote 14-14-16, N-P-K; Sungro Horticulture Distribution Inc., Bellevue, WA). All experiments were conducted at North Dakota State University, Fargo during spring 2010.

Fully expanded leaves of 2-week-old plants were spray inoculated until runoff with a chemical propellant sprayer (Preval sprayer; Precision Valve Corp. Yonkers, NY). Following inoculation, plants were placed in a mist chamber for $24 \mathrm{~h}$ at $22^{\circ} \mathrm{C}$ to facilitate infection. The plants were then transferred to a growth chamber programmed for a 22 and $18^{\circ} \mathrm{C}$ diurnal temperature and a 16-h photoperiod. Wheat accessions were arranged in a completely randomized design with three replicates and were considered as fixed effects. In each replication, three plants were assessed for disease reactions 8 days after inoculation. Disease reactions on the second leaf of each plant were scored using an ordinal rating scale of 0 to 5 (36), where accessions $\leq 2$ were classified as resistant and those with scores $>2$ were classified as susceptible. Phenotypic data were analyzed using the SAS program (SAS Institute, Cary, NC) to determine significant interaction $(P \leq 0.0001)$ between replications and wheat accessions, and Bartlett's $\chi^{2}$ was performed to test the homogeneity of variances (SAS Institute).
Genotyping. DNA used in the previous association analysis for races 1 and 5 (28) were used for comparative mapping. All wheat accessions were genotyped with DArT markers from a PstI/Bst $\mathrm{NI}$ representation and each DArT marker was designated by the prefix "wPt" (http://www.triticarte.com.au). In total, 2,500 DArT markers located on wheat chromosomes were used to genotype the 567 accessions as described previously (4).

Association testing. Marker property, LD, hierarchical clustering, and $\mathrm{Q}+\mathrm{K}$ mixed model analyses were performed using the JMP Genomics statistical suite (SAS Institute). Initially, minor allele frequency (MAF) and the proportion of missing genotypes were calculated for all 832 marker variables. DArT loci with $<0.05$ MAF and $>0.15$ missing genotypes were removed, leaving 625 loci with known consensus map locations provided by Diversity Arrays Technologies PTL that were used to calculate LD and a relationship matrix $(\mathrm{Q}$ and $\mathrm{K}$ ). In all, $>80$ wheat populations (recombinant-inbred lines, doubled haploid, $\mathrm{F}_{2}$ ) were genotyped with a set of whole genome-derived DArT markers to develop consensus maps of all wheat chromosomes (4) (A. Kilian, personal communication). In consensus maps, genetic distances are provided in centimorgans $(\mathrm{cM})$. LD and allele frequency correlations $\left(r^{2}\right)$ were calculated according to Weir (53) and LD value was calculated separately for loci on the same chromosome and unlinked loci in each chromosome and later combined across the $\mathrm{A}, \mathrm{B}$, and D genomes (15). A critical value of $r^{2}$ was estimated (10) using the 95 percentile of the $r^{2}$ root transformation distribution. Nonlinear regression using PROC NLIN in SAS 9.1.3 (SAS Institute) was used to determine LD decay as a function of the distance where $20 \%$ of the alleles between two loci are shared. To account for structure, all pairwise marker-to-marker $(n=625$ DArT $)$ correlation coefficients were calculated and used to perform PCA (Q) and develop a pairwise allele-sharing similarity (AS) matrix (K). Subsequently, hierarchical clustering was performed using Ward's method and a heat plot was generated to visualize relationships not accounted for clustering.

A Q-K MLM was used to analyze numeric DArT genotypes for association with ordinal SNB traits (56). Three principal components calculated from the relationship matrix were used as the Q matrix variables in the model and values from the AS matrix were imputed as $\mathrm{K}$ matrix variables. Because the discrete distribution of the ordinal trait was not normal, the residual pseudolikelihood estimation method in PROC GLIMMIX was used with no constraint of the $\mathrm{K}$ matrix covariance parameter. Because dominance and additive effects were not assumed, association tests were performed treating genotypes as categorical variables in analysis of variance (dominance model) and as quantitative variables in regression analyses (additive model). The negative $\log _{10}$ conversion was used on all calculated $P$ values and the tests were performed with and without the false discovery rate (FDR) multiple testing correction. Phenotypic variation explained by a particular marker $\left(R^{2}\right)$ was calculated based on the $F$ statistic and numerator and denominator DF as described by previously (14).

\section{RESULTS}

Phenotypic analysis across wheat accessions. In all, $\approx 85.5 \%$ of the accessions were susceptible to $P$. nodorum, exhibiting average disease scores of 2.1 to 5 (Fig. 1). The remaining $14.5 \%$ of the accessions were resistant, with average disease scores of 0 to 2 (Fig. 1). Within the resistant accessions, 10 accessions had disease scores of 0 to 1 while 72 accessions had disease scores of 1.1 to 2 . No significant interaction $(P \leq 0.0001)$ between wheat accessions and replications was observed. However, wheat accessions were highly significant $(\mathrm{df}=566, F$ value 14.75 , and $P \leq$ $0.0001)$. Phenotypic data were homogeneous (Bartlett's $\chi_{\mathrm{df}=2}^{2}=$ 9.99, and $P=0.068$ ). Therefore, data were combined and overall means were used for association analysis in order to identify putative genomic regions associated with resistance to $P$. nodorum. 
Phenotypic analysis based on geographic origin. There were significant differences in the proportion of resistant accessions by origin, with Asia having a lower percentage of resistant accessions compared with the Americas, Africa, and Europe (Table 1). When distribution of wheat accessions resistant to $P$. nodorum was partitioned by continent, Asia had the largest number $(n=35)$ of resistant accessions (Table 1). Of the 35 resistant accessions identified from Asia, Iran had the most $(n=8)$ resistant accessions followed by Turkey $(n=5)$, and China $(n=4)$ (Supplementary Table 1). Fourteen resistant accessions were from Europe. In particular, Greece and Russia each had four resistant accessions from Europe. Among the 16 resistant accessions from Africa, Ethiopia had 8 resistant accessions, followed by Eritrea $(n=4)$. Of the 17 resistant accessions detected from the Americas, Bolivia and Peru had the highest number, with 7 and 4 resistant accessions, respectively. Only one resistant accession was from Mexico.

Marker statistics and linkage disequilibrium. Of the 2,500 DArT markers analyzed, almost 33\% (832 DArT markers) were polymorphic and the remaining nonpolymorphic DArT markers were not included in data analysis. Among the 832 polymorphic markers, 747 markers had MAF $>0.05$ and $<0.15$ missing genotypic data in the 567 spring wheat accessions. Of the DArT loci, $122(16.3 \%)$ did not have known map positions and were removed from further analyses. DArT markers were mostly distributed on the A and B genomes (39.7 and $38.1 \%$, respectively), with the fewest markers distributed across the D genome (22.2\%) as expected. A higher portion of DArT markers were found on chromosomes $1 \mathrm{~A}, 3 \mathrm{~B}, 6 \mathrm{~A}$, and $7 \mathrm{D}$, with the greatest distribution on chromosome 6A (Fig. 2). The proportion of unique DArT

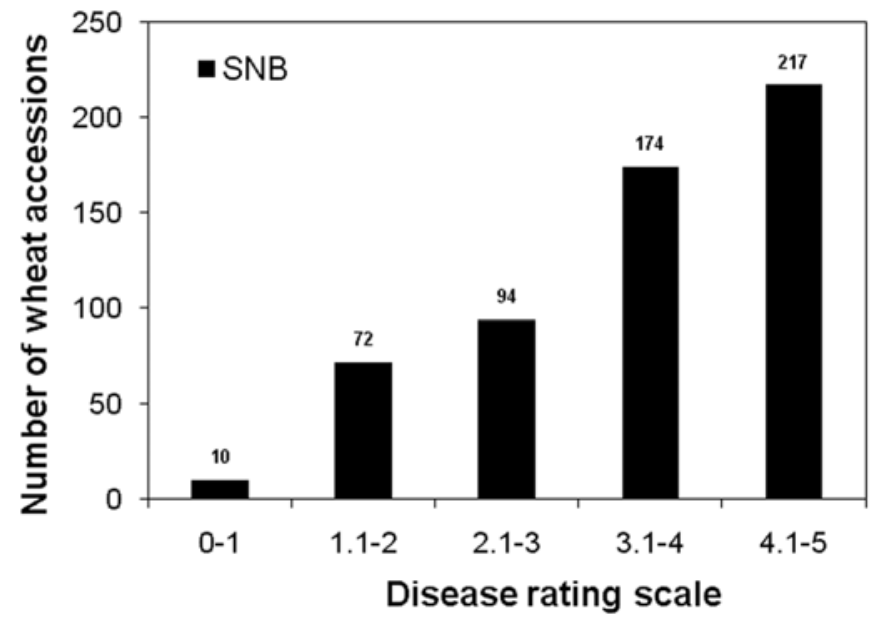

Fig. 1. Disease reactions of 567 spring wheat landraces to Phaeosphaeria nodorum. Wheat accessions were grown in growth chambers and disease reactions on the second leaf of each plant were scored 8 days after inoculation using an ordinal rating scale of 0 to 5 (36), where accessions $\leq 2$ were classified as resistant and those with scores $>2$ were classified as susceptible.

TABLE 1. Reactions of spring wheat landraces to Phaeosphaeria nodorum evaluated in a greenhouse in North Dakota ${ }^{\mathrm{x}}$

\begin{tabular}{lrcc}
\hline Region & $n$ & Number of resistant & Resistant $(\%)^{\mathrm{y}}$ \\
\hline Americas & 38 & 17 & $44.7 \mathrm{~b}$ \\
Europe & 63 & 14 & $22.2 \mathrm{~b}$ \\
Asia & 389 & 35 & $9.0 \mathrm{a}$ \\
Africa & 73 & 16 & $22.2 \mathrm{~b}$ \\
Total $^{\mathrm{z}}$ & 567 & 82 & 14.5 \\
\hline
\end{tabular}

${ }^{x}$ Based on three replications of three plants per replication. Disease reactions were assessed 8 days after inoculation using on ordinal rating scale of 0 to 5 (34), where accessions $\leq 2$ were classified as resistant and those with scores $>2$ were classified as susceptible.

y Percentages followed by the same letter not significantly different by nonoverlap of the $95 \%$ binomial confidence interval.

${ }^{\mathrm{z}}$ Four accessions of unknown origin included in total.

positions on each chromosome averaged 54.5\%; however, chromosomes 4B, 5A, and 5D only had one position, while no DArT markers were found on chromosome 4D (Fig. 2).

Data analysis showed that $44 \%$ of the 14,938 intrachromosomal marker pairs had a significant level of $\operatorname{LD}(P<0.01)$, and average $r^{2}$ for all pairs was 0.058 (data not shown). A critical value for significance was fixed at $r^{2}=0.049$ and considered as upper limit. All of the LD values beyond this value $\left(r^{2}=0.049\right)$ were expected due to genetic linkage (10). LD analysis revealed that genomewide $r^{2}$ estimates declined rapidly to 0.2 within $5 \mathrm{cM}$ of genetic distance. Specifically, LD decayed rapidly $(\leq 2 \mathrm{cM})$ on 9 of the 17 chromosomes having more than one unique position while chromosomes $1 \mathrm{D}, 6 \mathrm{~B}$, and $6 \mathrm{D}$ had the highest $\mathrm{LD}$ when more than 12 unique DArT positions were used. It is important to point out that, although chromosome 3D had the highest extent of LD $(18 \mathrm{cM})$, only three unique DArT positions (11, 37.5, and $151.8 \mathrm{cM}$ ) were retained for the analysis (Table 2).

Population structure. PCA showed that $40.5 \%$ of the variation was explained by a single component, while an additional $19.2 \%$ of the variation was explained when a second (10.5\%) and third $(8.7 \%)$ were included (Fig. 3A). Overall, a total of $59.7 \%$ of the

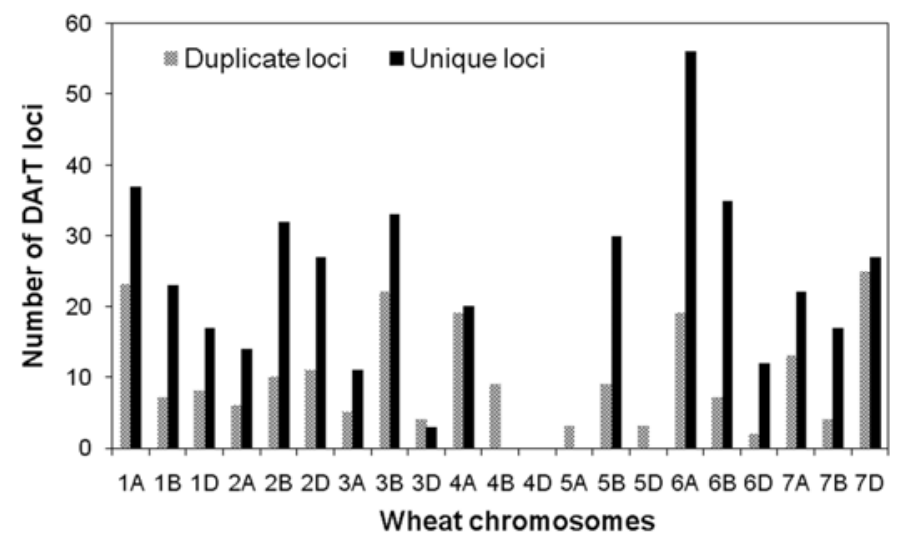

Fig. 2. Diversity array technology (DArT) marker distribution and linkage disequilibrium by chromosome based on 625 loci. Distributions are based on number of duplicate loci (scatter bar graph) and unique positions (solid bar graph) on each chromosome. DArT marker placement and positions were based on information from DArT PTL.

TABLE 2. Genetic marker statistics and linkage disequilibrium (LD) decay based on specific chromosomes

\begin{tabular}{|c|c|c|c|c|}
\hline Chromosome $^{\mathrm{z}}$ & $\begin{array}{l}\text { Number } \\
\text { of loci }\end{array}$ & $\begin{array}{l}\text { Number of } \\
\text { positions }^{\mathrm{z}}\end{array}$ & $\begin{array}{c}\text { Average } \\
\text { distance }(\mathrm{cM})\end{array}$ & $\begin{array}{l}\text { LD decay } \\
\text { (cM) }\end{array}$ \\
\hline $1 \mathrm{~A}$ & 60 & 37 & 3.6 & 1.8 \\
\hline $1 \mathrm{~B}$ & 30 & 23 & 4.4 & 1.8 \\
\hline $1 \mathrm{D}$ & 25 & 17 & 4.5 & 6.5 \\
\hline $2 \mathrm{~A}$ & 20 & 14 & 7.6 & 2.4 \\
\hline $2 \mathrm{~B}$ & 42 & 32 & 4.1 & 2.1 \\
\hline $2 \mathrm{D}$ & 38 & 27 & 2.1 & 1.8 \\
\hline $3 \mathrm{~A}$ & 16 & 12 & 15.9 & 2.5 \\
\hline $3 B$ & 55 & 32 & 3.9 & 2.1 \\
\hline $3 \mathrm{D}$ & 7 & 3 & 70.4 & 18.0 \\
\hline $4 \mathrm{~A}$ & 39 & 19 & 4.6 & 0.8 \\
\hline $4 \mathrm{~B}$ & 9 & 1 & $\ldots$ & $\ldots$ \\
\hline $4 \mathrm{D}$ & $\ldots$ & $\ldots$ & $\ldots$ & $\ldots$ \\
\hline $5 \mathrm{~A}$ & 3 & 1 & $\ldots$ & $\ldots$ \\
\hline $5 B$ & 39 & 30 & 4.8 & 2.0 \\
\hline $5 \mathrm{D}$ & 1 & 1 & $\ldots$ & $\ldots$ \\
\hline $6 \mathrm{~A}$ & 75 & 46 & 2.4 & 1.8 \\
\hline $6 \mathrm{~B}$ & 42 & 34 & 3.4 & 4.0 \\
\hline $6 \mathrm{D}$ & 14 & 12 & 11.9 & 9.0 \\
\hline $7 \mathrm{~A}$ & 35 & 22 & 8.1 & 0.8 \\
\hline $7 \mathrm{~B}$ & 21 & 17 & 9.7 & 1.0 \\
\hline 7D & 52 & 27 & 6.8 & 1.2 \\
\hline
\end{tabular}



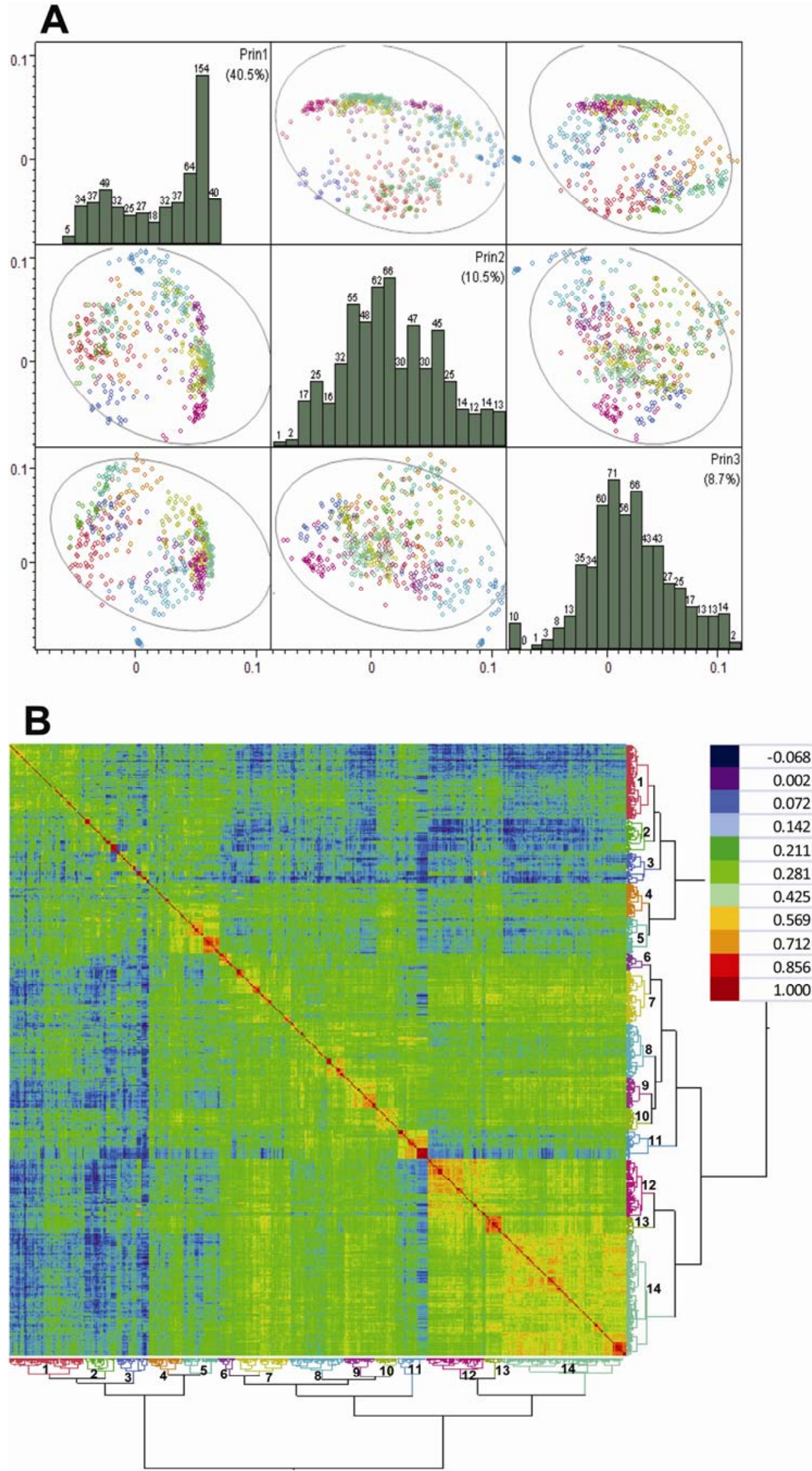

Fig. 3. Population structure of 554 spring wheat accessions analyzed based on A, principal component (PC) and B, allele-sharing similarity analyses. Three PCs were used in the analysis and the overall graph showed 2D comparisons using PC1 in the first row and column, PC2 in the second row and column, and PC 3 in the third row and column. Hierarchical clustering was based on Ward's method and the heat plot was based on allele-sharing coefficients. Within the heat plot, red indicates the highest proportion of shared alleles and blue indicates the lowest. Dot and cluster colors are consistent between figures. Fourteen clusters were separated by different colors. Value in each cluster represented cluster number. 
variation was explained by the first three components. Hierarchical clustering and allele-sharing coefficients revealed two distinct divisions that could be subdivided into 14 clusters (Fig. 3B; Supplementary Table 2). Wheat accessions in the first division were separated into clusters 1 to 5 , while accessions in the second division were separated into clusters 6 to 14 . Geographic origin generally corresponded to clustering based on the markers. Most accessions originating from eastern Africa, eastern Asia, northern Africa, South America, southern Europe, and western Europe grouped with clusters 1 to 5 whereas most of the accessions from south-central Asia and western Asia grouped within clusters 6 to 14. Accessions in clusters 1, 2, and 3 were very distinct from one another, whereas half the accessions in cluster 4 shared a fair amount of alleles with those in cluster 5 . Within the second division, accessions in a cluster were very similar while a majority of the accessions in clusters 12,13 , and 14 shared the largest proportion of alleles. Additionally, accessions in clusters 7, 9, and 10 shared a fair amount of alleles with accessions in clusters 12,13, and 14. Between the two divisions, only accessions in clusters 3 and 12 shared a large percent of alleles (Fig. 3B).
Association analysis of resistance to $P$. nodorum. For the entire data set, 24 markers located on chromosomes 1A, 2D, 3B, 5B, 6A, and 7A were associated $(P<0.05)$ with SNB resistance (Fig. 4). Seven markers on chromosomes 2D, 3B, 5B, 6A, and 7A remained significant after correcting for multiple testing using the positive FDR criterion ( $Q$ value $<0.01$ ) (Table 3$)$. Of these markers, three were mapped to a $12-\mathrm{cM}$ region $(73$ to $85 \mathrm{cM}$ ) on chromosome 2D (Fig. 4) that each accounted for $>10.0 \%$ of the phenotypic variation (Table 3 ). Phenotypic class mean indicates that resistance associated with no allele. When combined, these loci explained phenotypic variation of 2.2 to $12.2 \%$ (Table 3 ).

\section{DISCUSSION}

Host resistance is an economically feasible option to manage $P$. nodorum. Until now, five HSTs (such as SnToxA, SnTox1, SnTox2, SnTox3, and SnTox4) have been identified from this pathogen $(1,22,26,34,35)$. Wheat- $P$. nodorum interactions demonstrated that the fungus was able to produce these toxins in wheat cultivars with dominant susceptibility genes such as Tsn1, Snn1, Snn2, Snn3, and Snn4 (1,22,24,34,35). These five major genes
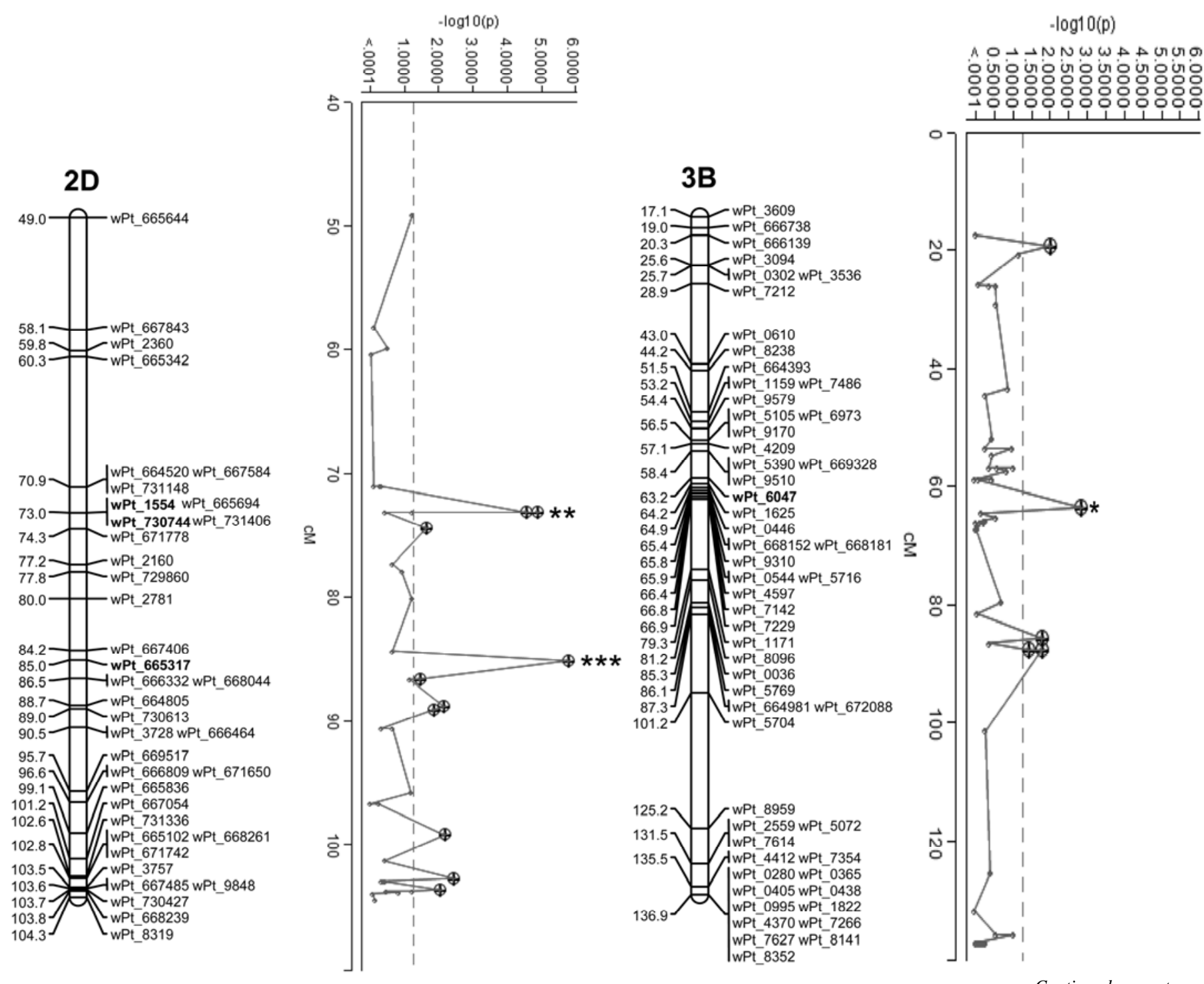

Continued on next page

Fig. 4. Association mapping profiles of resistance to Phaeosphaeria nodorum. Consensus linkage maps are based on information from Diversity Arrays Technology PTL. On the left, values are genetic distance in centimorgans (cM). On the right, diversity array technology markers (bold) are significantly associated with resistance to Stagonospora nodorum blotch. In the current figures, the genetic linkage maps align directly with the $P$ value plot. In negative $\log _{10} p$ plots (right), the dotted line indicates the significance threshold without false discovery rate correction, and values marked with *,**, and *** indicate significance at $P=0.5,0.01$, and 0.001 , respectively. 
and a few other minor QTL responsible for resistance to $P$. nodorum have been identified from wheat cultivars and advanced breeding lines $(1,22,23,34,35)$. Friesen and Faris (22) suggested that there might be more uncharacterized interactions which need further study. Because P. nodorum undergoes frequent sexual recombination $(2,30)$, there is a high risk of increased virulence within the pathogenic populations due to natural selection. Thus, identification of new sources of resistance to $P$. nodorum is necessary. In this study, we applied an AM approach and found 24 DArT markers located on wheat chromo-

TABLE 3. Identification of genomic regions involved in resistance to Phaeosphaeria nodorum in spring wheat landraces using association analysis accounting for positive false discovery rate ( $\mathrm{pFDR})$

\begin{tabular}{|c|c|c|c|c|c|c|c|c|}
\hline DArT locus ${ }^{\mathrm{s}}$ & Chromosome $^{t}$ & Position $^{\mathrm{u}}$ & $P$ value $^{\mathrm{v}}$ & $\mathrm{pFDR}^{\mathrm{w}}$ & $R^{2 \mathrm{x}}$ & LS mean $(2)^{\mathrm{y}}$ & LS mean $(0)^{y}$ & Diff. $^{z}$ \\
\hline wPt-1554 & $2 \mathrm{D}$ & 73.0 & 0.000032 & 0.0035 & 0.101 & 3.49 & 3.40 & 0.09 \\
\hline wPt-730744 & $2 \mathrm{D}$ & 73.0 & 0.000018 & 0.0025 & 0.109 & 3.43 & 4.85 & -0.05 \\
\hline wPt-665317 & $2 \mathrm{D}$ & 85.0 & 0.000002 & 0.0007 & 0.119 & 2.51 & 3.58 & -1.07 \\
\hline wPt-1149 & $5 \mathrm{~B}$ & 28.4 & 0.001144 & 0.0651 & 0.022 & 3.33 & 3.67 & -0.34 \\
\hline wPt-7330 & $6 \mathrm{~A}$ & 8.2 & 0.001162 & 0.0651 & 0.022 & 3.07 & 3.56 & -0.49 \\
\hline wPt-4515 & $7 \mathrm{~A}$ & 55.1 & 0.000019 & 0.0025 & 0.122 & 3.24 & 3.82 & -0.58 \\
\hline
\end{tabular}

${ }^{\mathrm{s}}$ Diversity array technology (DArT) markers used for detecting quantitative trait loci (QTL) for resistance to Stagonospora nodorum blotch (SNB) in 567 spring wheat accessions.

${ }^{t}$ Chromosome number where the DArT marker was mapped.

"Genetic distance in centimorgans (cM).

${ }^{v} P$ values adjusted after multiple tests were highly significant at $P<0.001$

${ }^{\text {w }}$ Analyses with no $P$ value adjustment were performed with and without the FDR multiple testing correction.

x Phenotypic variation explained by the markers.

${ }^{y}$ LS mean $=$ linear combination (sum) of the estimated effects (means) from the linear model, $2=$ DArT hybridization or present, and $0=$ no hybridization or absent

${ }^{\mathrm{z}}$ Differential effect when DArT is present.

$-\log 10(p)$

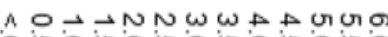

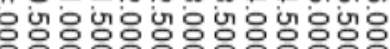
응ㅇㅇㅇㅇㅇㅇㅇㅇㅇㅇㅇㅇㅇㅇㅇㅇㅇㅇㅇㅇ

5B

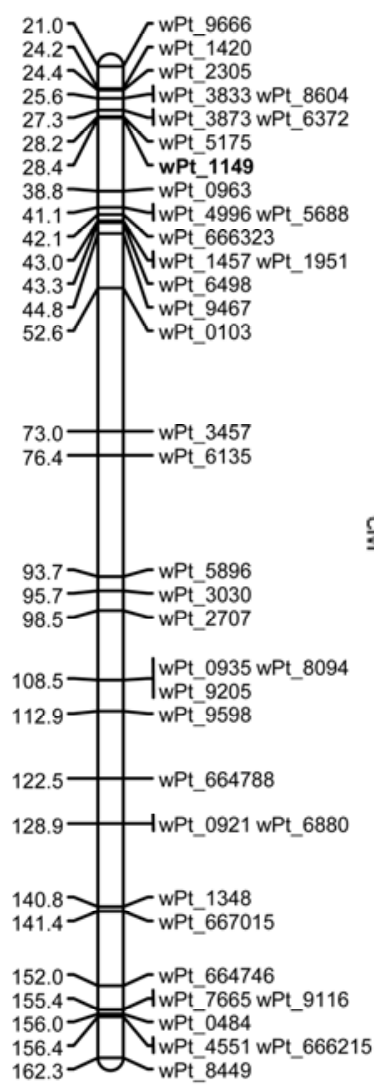

\section{A}

$\left.\begin{array}{l}0.2 \\ 0.7 \\ 3.9 \\ 4.2 \\ 6.4 \\ 7.9 \\ 8.2\end{array}\right]$ [1.9.

16.3

16.8 wPt 5652

17.1 $-\left[\right.$ wPt $^{-7} 731250$

$17.5]=\left[\begin{array}{l}\text { wPt } \\ \text { - }\end{array}\right.$

17.5 19 WPt_666074

- WPt- 3524

20.5 - wPt 7906

22.8 [wPt_665036 wPt_666988

22.8 WPt 730631

23.3 - LWPt_667405 wPt_668000

23.3 - wPt_671638 wPt_7304

23.6 - 1 WPt_3965 wPt_7623

24.2

24.2 wPt $^{-}$730729 wPt $^{-} 731010$

wPt-8539

29.1 - WPt

29.4 wPt_671708 wPt 730109

30.3 - wPt $730368 \mathrm{wPt}^{-} 730456$

wPt_730711 wPt_731413

32.2 - WPt 666224

36.7 - wPt 729806

49.2- $=$ HWPt_664792 wPt 730772

53.7 wPt_730769

82.7 1 wPt 665169

83.6 wPt 671568

84.6

89.8 $=1$ wPt 0696

92.3 - WPt-731524

93.1 I WPt_5696 wPt_672030

93.9 - wPt 731120

94.9 -WPt_666494

95.2] = 4wPt_665805 wPt 730338

99.0 1 wPt 731002

104.1

105.

105.5 WPt 730629

$\left.\begin{array}{l}107.8 \\ 108.4\end{array}\right] \quad\left[\begin{array}{l}\text { wPt_3247 wPt_4229 } \\ \text { wPt_8124 wPt_9474 } \\ \text { wPt_1661 }\end{array}\right.$ $-\log 10(p)$

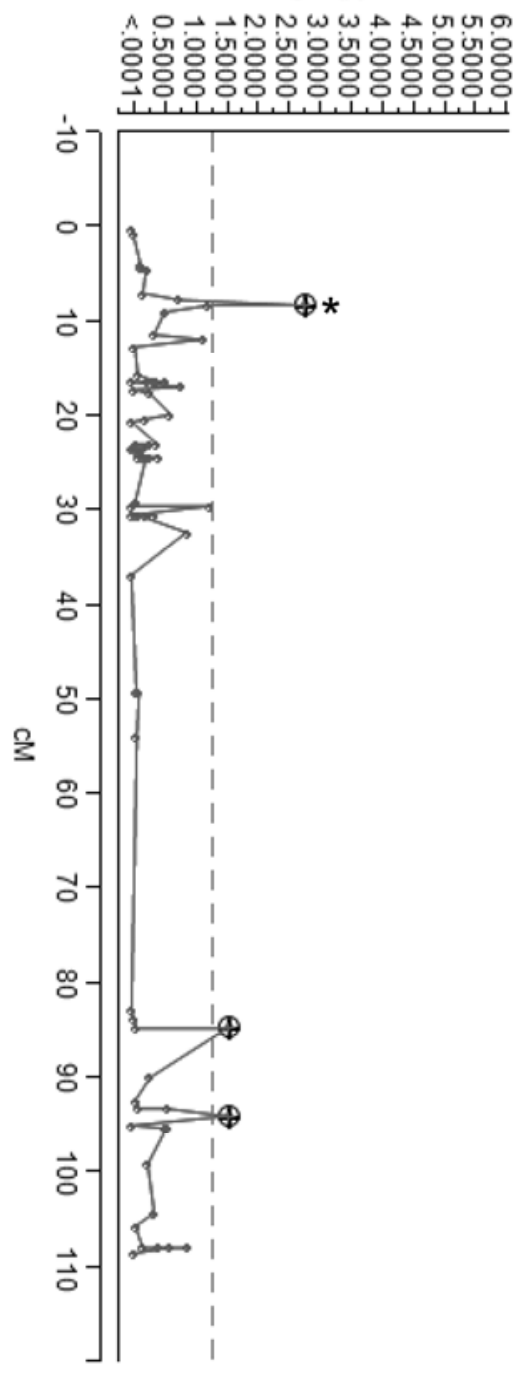

Fig. 4. (Continued from previous page). 
somes 1A, 2D, 3B, 5B, 6A, and 7A that were significantly associated with resistance to $P$. nodorum when no multiple testing correction was applied. Of these, seven markers (wPt-1554, $w P t-730744, w P t-665317, w P t-6047, w P t-1149, w P t-7330$, and $w P t-4515)$ remained significant after correction was applied. These regions on chromosomes $2 \mathrm{D}, 3 \mathrm{~B}$, and $5 \mathrm{~B}$ correspond to previously known QTL to be involved in resistance to $P$. nodorum $(22,34,35,46)$, whereas the remaining loci located on chromosomes $6 \mathrm{~A}$ and 7A appeared to be novel, suggesting that genetic regions around these loci may be useful for incorporating new resistance to $P$. nodorum in wheat breeding programs. In addition, information on genetic diversity, population structure, and LD in these spring wheat landraces of diverse origin also provides a conceptual framework for designing new breeding strategies and utilizing these novel alleles in wheat improvement program.

In this study, AM identified marker-trait associations in a subset of spring wheat landraces representing the broad geographic origin in the NSGC. A higher proportion of spring wheat landrace resistance to $P$. nodorum was found in accessions from the Americas, Europe, and Africa compared with Asia. With the exception of southern Europe and eastern Africa, this result contrasts with the occurrence of resistance to other diseases found previously. For example, stem rust resistance was most frequent in landrace accessions from south-central Asia, western Asia, and eastern Africa (9), and common and dwarf bunt resistance was most frequent in accessions originating from the western Asia, southcentral Asia and southern Europe (8).
7A

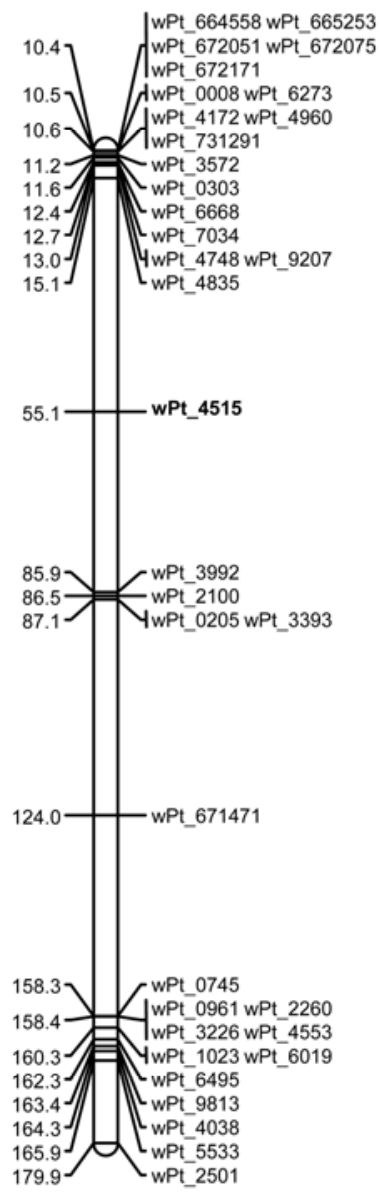

$-\log 10(\mathrm{p})$

A $\rightarrow \rightarrow N N \omega \omega \rightarrow+G M R$ 응ㅇㅇㅇㅇㅇㅇㅇㅇㅇㅇㅇㅇㅇㅇㅇㅇㅇㅇㅇㅇㅇㅇㅇㅇㅇ

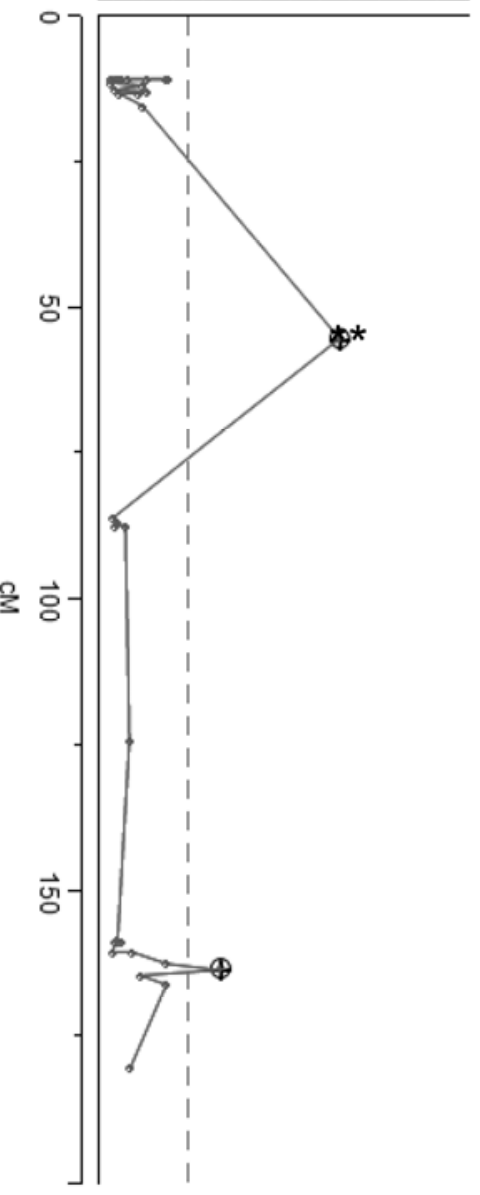

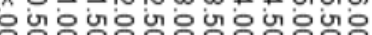

Fig. 4. (Continued from previous page).
The majority of wheat landraces that originated from Iran, Ethiopia, and Bolivia were resistant to $P$. nodorum. Iran is a part of the Fertile Crescent, which is the center of diversity and center of origin for most of the members of the tribe Triticeae, including wheat. This result suggests that we might find additional sources of resistance to $P$. nodorum from Iran and other countries in the Fertile Crescent region. Apart from Iran, most of the SNBresistant landraces were from Ethiopia and Bolivia. The resistant landraces of different geographic origin also differed based on DArT marker haplotype and, thus, could carry different resistance genes, which could be deployed in resistance wheat breeding programs. A few landraces have poor agronomic characteristics and some prebreeding will be needed to transfer resistance into adapted genotypes for use by U.S. spring wheat breeding programs.

The number of spurious marker-trait associations can be exaggerated due to the differential relatedness among subgroups, or population structure (43). In this study, population structure analysis separated the entire collection of spring wheat landraces into 14 subpopulations. The number of false-positive QTL can be minimized by identifying and accounting for structures in AM populations (58). The MLM accounting for Q and K revealed significant marker-trait associations and identified five genomic regions involved in resistance to $P$. nodorum. AM has been successfully applied to identify markers responsible for disease resistance in maize (33), potato (39), barley (45), and wheat $(12,28,51)$.

AM showed the association between the marker and the trait by strength of LD held between them across a set of diverse germplasms or set of inbred lines by exploiting historical and evolutionary recombination events at the population level (41). In this study, both LD analysis and association analysis were performed simultaneously. For LD decay analysis, we used 625 DArT markers with known chromosome positions in order to calculate LD statistics $\left(r^{2}\right)$ between DArT markers. For association analysis, we used only a set of 309 DArT markers with LD < 0.5 , with all other random markers to estimate factors that would control population structure. This was necessary to obtain a subset of nonredundant and unlinked loci to reduce biasness in the study. Wheat genome D (e.g., 3D, 4D, and 5D) had small numbers of DArT marker distribution in order to calculate the reliable LD for those chromosomes. In contrast, the chromosomes where we found significant markers associated with resistance to $P$. nodorum had good numbers of marker distribution to calculate reliable LD/LD decay. A scatter plot of $r^{2}$ values versus genetic distances between all markers across the genome abruptly declined to 0.2 within $5 \mathrm{cM}$ when all maps were analyzed. This result was expected for self-pollinated crop species such as wheat. A rapid rate of inbreeding with selfing results in a low recombination frequency in such self-pollinated species (57).

In the previous studies, the estimated LD decay of wheat was 0.5 to $40 \mathrm{cM}(10-12,15,38)$, which is relatively high when compared with other cross-pollinated crops such as maize (200 to $2,000 \mathrm{bp})$ and Arabidopsis ( $<10 \mathrm{~kb})(31,50)$. The estimated genome-wide LD decay in this study varied between $\approx 1$ and $10 \mathrm{cM}$. It is important to note that the quality of the LD value is highly conditioned by the distribution of markers. The estimated LD decay values also varied according to wheat types and marker systems (e.g., microsatellites and DArT) used. Therefore, LD decay values should not be compared and generalized. In addition, the LD decay values obtained from a single genome (i.e., either A, B, or D) should not be compared with whole-genome LD. The LD decay from 10 to $40 \mathrm{cM}$ was detected when advanced breeding lines or wild wheat populations were analyzed by microsatellite and DArT markers $(11,12,15)$. In this study, the LD decay value was obtained from spring wheat landraces with wide geographic variations using DArT markers for whole A, B, and D genomes.

Of the five putative genomic regions identified with AM, three regions were located on the same chromosomes (2D and $5 \mathrm{~B}$ ), 
where designated genes for sensitivity (e.g., Snn2, Snn3, and $T s n 1$ ) to $P$. nodorum toxins had been mapped previously (22). One distinct candidate genomic region on chromosome $2 \mathrm{D}$ spanning a gap of 73.0 to $85.0 \mathrm{cM}$ was found significantly associated with three markers. Similarly, another candidate genomic region on $5 \mathrm{~B}$ also was found significantly associated with the wPt-1149 marker. The present study identified a genomic region on 6A where Liu et al. $(34,35)$ previously mapped a minor QTL. There are also previous reports for resistance to $P$. nodorum on chromosome $3 \mathrm{~B}$ $(15,46)$. However, the remaining genomic region $7 \mathrm{~A}$, which has the largest effect $(\approx 12 \%)$, appeared to be novel because no previous reports of QTL for resistance to P. nodorum exist.

To determine whether any known resistance genes coincide with the putative genomic regions identified in this study, two DArT markers ( $w P t-6047$ on 3B and $w P t-7330 / w P t-9075$ on 6A) significantly associated with resistance to $P$. nodorum were associated with resistance to leaf rust $(L r)$, powdery mildew $(P m)$, and yellow rust $(Y r)$, and QTL for grain yield (12). The DArT marker $w P t-6047$, located at $63.18 \mathrm{cM}$ on chromosome 3B, was previously reported to be associated with QTL responsible for grain yield (5) and other QTL responsible for leaf rust and yellow rust (12). Although three toxin sensitivity genes-Snn2, and Snn3 and Tsn1-were mapped using the expressed sequence tag (EST)based markers and SSR on the wheat chromosomes 2D and 5B, respectively (22), it is difficult to compare and find the exact locations of these genes due to different marker systems used in the previous study (22). Further work is needed to determine whether our QTL correspond to these three genes. Nonetheless, the genomic regions reported here and identified in the previous studies can be suitable for MAS.

The QTL responsible for resistance to $P$. nodorum had small phenotypic effects $\left(R^{2}\right)$ of 2.2 to $12.0 \%$. Several previous studies had shown that resistance to $P$. nodorum is complex due to its quantitative nature and polygenic inheritance $(22,34)$. Kump et al. (33) identified 32 QTL with predominantly small, additive effects on Southern leaf blight disease in maize using AM. Massman et al. (40) found that small QTL effects explaining 1 to $3 \%$ of the phenotypic variation in FHB resistance, presumably due to resistance, were complex and polygenic. A small phenotypic variation effect of 2.3 to $3.9 \%$ also was observed in AM of resistance to spot blotch in wild barley (45).

AM analyses revealed that the genomic regions on chromosomes $2 \mathrm{D}$ and $5 \mathrm{~B}$ can play important roles in conferring resistance to both $P$. nodorum and $P$. tritici-repentis in wheat. A DArT marker significantly associated with resistance to both SNB and $P$. tritici-repentis race 1 was found on chromosomes $2 \mathrm{D}$. In particular, the DArT marker $w P t-730744$ was associated with resistance to $P$. nodorum and $P$. tritici-repentis race 1 (28). In the previous studies, a QTL for flag leaf resistance in the 05Y001 mapping population contributed by 'EGA Blanco' (20), and QTL for flag leaf resistance in the mapping population developed from a cross between 'BR' and 'Grandin' wheat, were mapped on chromosome 5B (22). This QTL was co-localized with a dominant gene, Tsnl for sensitivity to Ptr ToxA (22), which was previously mapped to the long arm of chromosome 5B (18). A gene functionally identical to ToxA was discovered and designated SnToxA in P. nodorum (25). Both ToxA-Tsn1 and SnToxA-Tsn1 interactions are important for disease development caused by these two necrotrophic fungal pathogens in wheat $(19,25,35)$.

Recently, a controversy has occurred over whether QTL residing on 5BL is a single QTL or are linked QTL and controlled by multiple genes. This happened when the 133 recombinant-inbred chromosome lines (RICL) of a tetraploid wheat mapping population was artificially inoculated with the pathogen and a new seedling-resistant QTL on $5 B L$ was identified $\approx 8.8 \mathrm{cM}$ proximal to the Tsn1 locus (27). Faris and Friesen (19) reevaluated the same population (85 of 133 RICL) and reported that $T_{s n 1}$ is responsible for sensitivity to Ptr ToxA. Furthermore, they claimed that it was only the locus controlling susceptibility to $P$. nodorum in tetraploid wheat (19). Although both studies were performed by the two groups in Fargo, ND, there were some discrepancies in terms of number of RICL, inoculums, methods, and conditions used in these studies. More recently, Francki et al. (20) found results similar to those of Gonzalez-Hernandez et al. (27), and reported an additional QTL on chromosome 5BL, which was significantly associated with markers $f c p 001$ and $f c p 620$ based on disease reactions in one environment in Australia, indicating that it may be related to the Tsn1-Ptr ToxA interaction for toxin sensitivity and insensitivity. However, another QTL identified on the same chromosome 5BL, based on disease reactions in another environment in Australia, was not associated with markers $f c p 001$ and $f c p 620$, providing evidence for the presence of multiple QTL on chromosome 5BL in controlling resistance to P. nodorum (20). Although some genomic regions conferring resistance to $P$. nodorum (22) and $P$. tritici-repentis (48) have been identified, few QTL identified in this study also correspond to previously mapped QTL. AM analyses detected additional novel genomic regions contributing to $P$. nodorum and $P$. tritici-repentis (28), which can possibly be used to develop wheat cultivars with broadspectrum resistance.

In conclusion, five genomic regions significantly associated with resistance to SNB were identified in diverse spring wheat landraces. Some genomic regions were new and some were confirmation of previously identified regions. The new genomic regions contributing to resistance to $P$. nodorum may be absent in current breeding populations. Although valuable genomic regions associated with resistance to $P$. nodorum were identified, an important question may arise concerning how to validate these QTL and use them in wheat breeding programs. One possible method for validating QTL would be to develop near-isogenic lines (NILs) in different genetic backgrounds via MAS backcrossing, and test them across multiple environments. In addition, the effectiveness of QTL should be determined by testing NILs against multiple HSTs of this pathogen. Alternatively, QTL with small effects could be increased in frequency in a breeding population through cycles of MAS for multiple QTL followed by intermating selected individuals via a recurrent selection (7).

\section{ACKNOWLEDGMENTS}

We thank the Wheat Research and Promotion Council, Minnesota; North Dakota Wheat Commission; State Board of Agricultural Research and Education, North Dakota; and USDA-ARS specific cooperative agreement 58-5366-0-133 for financial support for this project; and A. Kilian and S. Mamidi for their help for statistical analysis.

\section{LITERATURE CITED}

1. Abeysekara, N. S., Friesen, T. L., Keller, B., and Faris, J. D. 2009. Identification and characterization of a novel host-toxin interaction in the wheat-Stagonospora nodorum pathosystem. Theor. Appl. Genet. 120:117-126.

2. Adhikari, T. B., Ali, S., Burlakoti, R. R., Singh, P. K., Mergoum, M., and Goodwin, S. B. 2008. Genetic structure of Phaeosphaeria nodorum populations in the north-central and mid-western United States. Phytopathology 98:101-107.

3. Aguilar, V., Stamp, P., Winzeler, M., Winzeler, H., Schachermayr, G., Keller, B., Zanetti, S., and Messmer, M. M. 2005. Inheritance of field resistance to Stagonospora nodorum leaf and glume blotch and correlations with other morphological traits in hexaploid wheat (Triticum aestivum L.). Theor. Appl. Genet. 111:325-336.

4. Akbari, M., Wenzl, P., Caig, V., Carling, J., Xia, L., Yang, S., Uszynski, G., Mohler, V., Lehmensiek, A., Kuchel. H., Hayden, M. J., Howes, N., Sharp, P., Vaughan, P., Rathmell, B., Huttner, E., and Kilian, A. 2006. Diversity arrays technology (DArT) for high-throughput profiling of the hexaploid wheat genome. Theor. Appl. Genet. 113:1409-1420.

5. Arbelbide, M., and Bernardo, R. 2006. Mixed-model QTL mapping for kernel hardness and dough strength in bread wheat. Theor. Appl. Genet. 112:885-890.

6. Beattie, A. D., Edney, M. J., Scoles, G. J., and Rossnagel, B. G. 2010. 
Association mapping of malting quality data from western Canadian tworow barley cooperative trials. Crop Sci. 50:1649-1663.

7. Bernardo, R. 2008. Molecular markers and selection for complex traits in plants: Learning from the last 20 years. Crop Sci. 48:1649-1664.

8. Bonman, J. M., Bockelman, H. E., Goates, B. J., Obert, D. E., McGuire, P. E., Qualset, C. O., and Hijmans, R. J. 2006. Geographic distribution of common bunt and dwarf bunt resistance in landraces of Triticum aestivum subsp. aestivum. Crop Sci. 46:1622-1629.

9. Bonman, J. M., Bockelman, H. E., Jin, Y., Hijmans, R. J., and Gironella, A. I. N. 2007. Geographic distribution of stem rust resistance in wheat landraces. Crop Sci. 47:1955-1963.

10. Breseghello, F., and Sorrells, M. E. 2006. Association mapping of kernel size and milling quality in wheat (Triticum aestivum L.) cultivars. Genetics 172:1165-1177.

11. Chao, S., Zhang, W., Dubcovsky, J., and Sorrell, M. 2007. Evaluation of genetic diversity and genome-wide linkage disequilibrium among U.S. wheat (Triticum aestivum L.) germplasm representing different market classes. Crop Sci. 47:1018-1030.

12. Crossa, J., Burgueno, J., Dreisigacker, S., Vargas, M., Herrera Foessel, S. A., Lillemo, M., Singh, R. P., Trethowan, R., Warburton, M., Franco, J., Reynolds, M., Crouch, J. H., and Ortiz, R. 2007. Association analysis of historical bread wheat germplasm using additive genetic covariance of relatives and population structure. Genetics 177:1889-1913.

13. Czembor, P. C., Arseniuk, E., Czaplicki, A., Song, Q., Cregan, P. B., and Ueng, P. P. 2003. QTL mapping of partial resistance in winter wheat to Stagonospora nodorum blotch. Genome 46:546-554.

14. Edwards, L. J., Muller, K. E., Wolfinger, R. D., Qaqish, B. F., and Schabenberger, O. 2008. An $R^{2}$ statistic for fixed effects in the linear mixed model. Stat. Med. 27:6137-6157.

15. Emebiri, L. C., Oliver, J. R., Mrva, K., and Mares, D. 2010. Association mapping of late maturity $\alpha$-amylase (LMA) activity in a collection of synthetic hexaploid wheat. Mol. Breeding 26:39-49.

16. Eyal, Z. 1999. Septoria and Stagonospora diseases of cereals: A comparative perspective. Pages 1-25 in: Septoria on Cereals: A Study of Pathosystems. J. A. Lucas, P. Bowyer, and H. M. Anderson, eds. IACR Long Ashton Research Station, Bristol, UK

17. Eyal, Z., Scharen, A. L., Prescott, J. M., and van Ginkel, M. 1987. The Septoria Disease of Wheat: Concepts and Methods of Disease Management. CIMMYT, Mexico, D.F.

18. Faris, J. D., Anderson, J. A., Francl, L. J., and Jordahl, J. G. 1996. Chromosomal location of a gene conditioning insensitivity in wheat to a necrosis-inducing culture filtrate from Pyrenophora tritici-repentis. Phytopathology 86:459-463.

19. Faris, J. D, and Friesen, T. L. 2009. Reevaluation of a tetraploid wheat population indicates that the Tsn1-ToxA interaction is the only factor governing Stagonospora nodorum blotch susceptibility. Phytopathology 99:906-912.

20. Francki, M. G., Shankar, M., Walker, E., Loughman, R., Golzar, H., and Ohm, H. 2011. New quantitative trait loci in wheat for flag leaf resistance to Stagonospora nodorum blotch. Phytopathology 101:1278-1284.

21. Fried, P. M., and Meister, E. 1987. Inheritance of leaf and head resistance of winter wheat to Septoria nodorum in a diallel cross. Phytopathology 77:1371-1375.

22. Friesen, T. L., Chu, C. G., Liu, Z. H., Halley, S., and Faris, J. D. 2009. Host-selective toxins produced by Stagonospora nodorum confer disease susceptibility in adult wheat plants under field conditions. Theor. Appl. Genet. 118:1489-1497.

23. Friesen, T. L., and Faris, J. D. 2010. Characterization of the wheatStagonospora nodorum disease system: What is the molecular basis of the quantitative necrotrophic disease interaction? Can. J. Plant Pathol. 32:2028.

24. Friesen, T. L., Meinhardt, S. W., and Faris, J. D. 2007. The Stagonospora nodorum-wheat pathosystem involves multiple proteinaceous host selective toxins and corresponding host sensitivity genes that interact in an inverse gene-for-gene manner. Plant J. 51:681-692.

25. Friesen, T. L., Stukenbrock, E. H., Liu, Z. H., Meinhardt, S. W., Ling, H., Faris, J. D., Rasmussen, J. B., Solomon, P. S., McDonald, B. A., and Oliver, R. P. 2006. Emergence of a new disease as a result of interspecific virulence gene transfer. Nat. Genet. 38:953-956.

26. Friesen, T. L., Zhang, Z., Solomon, P. S., Oliver, R. P., and Faris, J. D. 2008. Characterization of the interaction of a novel Stagonospora nodorum host-selective toxin with a wheat susceptibility gene. Plant Physiol. 146:682-693.

27. Gonzalez-Hernandez, J. L., Singh, P. K., Mergoum, M., Adhikari, T. B., Kianian, S. F., Simsek, S., and Elias, E. M. 2009. A quantitative trait locus on chromosome 5B controls resistance of Triticum turgidum (L.) var. diccocoides to Stagonospora nodorum blotch. Euphytica 166:199-206.

28. Gurung, S., Mamidi, S., Bonman, J. M., Jackson, E. W., del Río, L. E., Acevedo, M., and Adhikari, T. B. 2011. Identification of novel genomic regions associated with resistance to Pyrenophora tritici-repentis races 1 and 5 in spring wheat landraces using association analysis. Theor. Appl. Genet. doi:10.1007/s00122-011-1645-1

29. Kang, H. M., Zaitlen, N. A., Wade, C. M., Kirby, A., Heckerman, D., Daly, M. J., and Eskin, E. 2008. Efficient control of population structure in model organism association mapping. Genetics 178:1709-1723.

30. Keller, S. M., McDermott, J. M., Pettway, R. E., Wolfe, M. S., and McDonald, B. A. 1997. Gene flow and sexual reproduction in the wheat glume blotch pathogen Phaeosphaeria nodorum (anamorph Stagonospora nodorum). Phytopathology 87:353-358.

31. Kim, S., Plagnol, V., Hu, T. T., Toomajian, C., Clark, R. M., Ossowski, S., Ecker, J. R., Weigel, D., and Nordborg, M. 2007. Recombination and linkage disequilibrium in Arabidopsis thaliana. Nat. Genet. 39:11511155.

32. King, J. E., Cook, R. J., and Melville, S. C. 1983. A review of Septoria diseases of wheat and barley. Ann. Appl. Biol. 103:345-373.

33. Kump, K. L., Bradbury, P. J., Wisser, R. J., Buckler, E. S., Belcher, A. R., Oropeza-Rosas, M. A., Zwonitzer, J. C., Kresovich, S., McMullen, M. D., Ware, D., Balint-Kurti, P. J., and Holland, J. B. 2011. Genome-wide association study of quantitative resistance to southern leaf blight in the maize nested association mapping population. Nat. Genet. 43:163-168.

34. Liu, Z. H., Faris, J. D., Meinhardt, S. W., Ali, S., Rasmussen, J. B., and Friesen, T. L. 2004. Genetic and physical mapping of a gene conditioning sensitivity in wheat to a partially purified host-selective toxin produced by Stagonospora nodorum. Phytopathology 94:1056-1060.

35. Liu, Z. H., Friesen, T. L., Ling, H., Meinhardt, S., Oliver, R. P., Rasmussen, J. B., and Faris, J. D. 2006. The Tsn1-ToxA interaction in the wheat-Stagonospora nodorum pathosystem parallels that of the wheat-tan spot system. Genome 49:1265-1273.

36. Liu, Z. H., Friesen, T. L., Rasmussen, J. B., Ali, S., Meinhardt, S. W., and Faris J. D. 2004. Quantitative trait loci analysis and mapping of seedling resistance to Stagonospora nodorum leaf blotch in wheat. Phytopathology 94:1061-1067.

37. Ma, H., and Hughes, G. R. 1995. Genetic control and chromosomal location of Triticum timopheevi derived resistance to Septoria nodorum blotch in durum wheat. Genome 38:332-338.

38. Maccaferri, M., Sanguineti, M. C., Natoli, E., Araus-Ortega, J. L., Ben salem, M., Bort, J., Chenenaoui, S., Deambtogio, E., Garcia del Moral, L., De Montis, A., El-Ahmed, A., Maalouf, F., Machlab, H., Moragues, M., Motawaj, J., Nachit, M., Nsarellah, N., Ouabbou, H., Roya, C., and Tuberosa, R. 2006. A panel of elite accessions of durum wheat (Triticum durum Desf.) suitable for association mapping studies. Plant Genet. Resour. 4:79-85

39. Malosetti, M., van der Linden, C. G., Vosman, B., and van Eeuwijk, F. A. 2007. A mixed-model approach to association mapping using pedigree information with an illustration of resistance to Phytophthora infestans in potato. Genetics 75:879-889.

40. Massman, J., Cooper, B., Horsley, R., Neate, S., Macky, R. D., Chao, S., Dong, Y., Schwarz, P., Muehlbauer, G. J., and Smith, K. P. 2010. Genomewide association mapping of Fusarium head blight resistance in contemporary barley breeding germplasm. Mol. Breeding 27:439-454.

41. Nordborg, M., Borevitz, J. O., Bergelson, J., Berry, C. C., Chory, J., Hagenblad, J., Kreitman, M., Maloof, J. N., Noyes, T., Oefner, P. J., Stahl, E. A., and Weigel, D. 2002. The extent of linkage disequilibrium in Arabidopsis thaliana. Nat. Genet. 30:190-193.

42. Price, A. L., Patterson, N. J., Plenge, R. M., Weinblatt, M. E., Shadick, N. A., and Reich, D. 2006. Principal components analysis corrects for stratification in genome-wide association studies. Nat. Genet. 38:904-909.

43. Pritchard, J. K., Stephens, M., and Donnelly, P. 2000. Inference of population structure using multilocus genotype data. Genetics 155:945959.

44. Ravel, C., Praud, S., Murigneux, A., Linossier, L., Dardevet, M., Balfourier, F., Dufour, P., Brunel, D., and Charmet, G. 2006. Identification of Glu-B1-1 as a candidate gene for the quantity of highmolecular-weight glutenin in bread wheat (Triticum aestivum L.) by means of an association study. Theor. Appl. Genet. 112:738-743.

45. Roy, J. K., Smith, K. P., Muehlbauer, G. J., Chao, S., Close, T. J., and Steffenson, B. J. 2010. Association mapping of spot blotch resistance in wild barley. Mol. Breeding 26:243-256.

46. Schnurbusch, T., Paillard, S., Fossati, D., Messmer, M., Schachermayr, G., Winzeler, M., and Keller, B. 2003. Detection of QTLs for Stagonospora glume blotch resistance in Swiss winter wheat. Theor. Appl. Genet. 107:1226-1234.

47. Shankar, M., Walker E., Golzar, H., Loughman, R., Wilson, R. E., and Francki M. G. 2008. Quantitative trait loci for seedling and adult plant resistance to Stagonospora nodorum in wheat. Phytopathology 98:886893.

48. Singh, P. K., Singh, R. P., Duveiller, D., Mergoum, M., Adhikari, T. B., and E. M. Elias. 2010. Genetics of wheat-Pyrenophora tritici-repentis interactions. Euphytica 171:1-13.

49. Stich, B., and Melchinger, A. E. 2009. Comparison of mixed-model 
approaches for association mapping in rapeseed, potato, sugar beet, maize, and Arabidopsis. BMC Genomics 10:94.

50. Tenaillon, M. I., Sawkins, M. C., Long, A. D., Gaut, R. L., Doebley, J. F., and Gaut, B. S. 2001. Patterns of DNA sequence polymorphism along chromosome 1 of maize (Zea mays spp. mays. L.). Proc. Natl. Acad. Sci. USA 98:9161-9166.

51. Tommasini, L., Schnurbusch, T., Fossati, D., Mascher, F., and Keller, B. 2007. Association mapping of Stagonospora nodorum blotch resistance in modern European winter wheat varieties. Theor. Appl. Genet. 115:697708.

52. Uphaus, J., Walker, E., Shankar, M., Golzar, H., Loughman, R., Francki, M., and Ohm, H. 2007. Quantitative trait loci identified for resistance to Stagonospora glume blotch in wheat in the USA and Australia. Crop Sci. 47:1813-1822.

53. Weir, B. S. 1996. Genetic Data Analysis II. Sinauer, Sunderland, MA

54. Wicki, W., Winzeler, M., Schmid, J. E., Stamp, P., and Messmer, M. 1999. Inheritance of resistance to leaf and glume blotch caused by Septoria nodorum Berk. in winter wheat. Theor. Appl. Genet. 99:1265-1272.

55. Yu, J., and Buckler, E. S. 2006. Genetic association mapping and genome organization of maize. Curr. Opin. Biotechnol. 17:155-160.

56. Yu, J., Pressoir, G., Briggs, W. H., Bi I. V., Yamasaki, M., Doebley, J. F., McMullen, M. D., Gaut, B. S., Nielsen, D. M., Holland, J. B., Kresovich, S., and Buckler, E. S. 2006. A unified mixed-model method for association mapping that accounts for multiple levels of relatedness. Nat. Genet. 38:203-208.

57. Zhang, D., Bai, G., Zhu, C., Yu, J., and Carver, B. F. 2010. Genetic diversity, population structure, and linkage disequilibrium in U.S. elite winter wheat. Plant Genome 3:117-127.

58. Zhao, K., Aranzana, M. J., Kim, S., Clare, L., Shindo, C., Tang, C., Toomajian, C., Zheng, H., Dean, C., Marjoram, P., and Nordborg, M. 2007. An Arabidopsis example of association mapping in structured samples. PLoS Genet. 3:71-82.

59. Zhu, C., Gore, M., Buckler, E. S., and Yu, J. 2008. Status and prospects of association mapping in plants. Plant Genome 1:5-20. 